\title{
National study on use of artificial intelligence in breast disease and cancer
}

\author{
EMIROGLU Mustafa ${ }^{1}$, ESIN Huseyin ${ }^{1}$, ERDOGAN Mihriban², UGURLU Levent ${ }^{1}$, \\ DURSUN Ayberk ${ }^{1}$, MERTOGLU Suleyman ${ }^{3}$, KIZILOGLU Ilker ${ }^{4}$, KARAALI Cem ${ }^{1}$
}

University of Health Sciences, Tepecik Training and Research Hospital, Department of General Surgery, Konak, Izmir, Turkey. dr.hesin@hotmail.com

\begin{abstract}
BACKGROUND: The aim of this study was to examine the thoughts, reservations, approaches and perspectives on the future of artificial intelligence (AI) held by physicians specializing in breast healthcare in our country.

METHODS: Our survey was sent to the members of the Federation of Turkish Breast Disease Associations (MHDF) by e-mail. The survey investigates the attitudes towards the use of $\mathrm{Al}$ in breast disease and cancer, including demographic characteristics of the participants, their daily practice and approaches, and their stance on the future.

RESULTS: The questionnaire was sent to a total of 1,890 people via e-mail. 108 (40.1\%) participants believed that the use of $\mathrm{Al}$ in breast disease would improve their field of expertise moderately, $103(38.3 \%)$ expected this improvement to be considerable. 169 (70.3\%) respondents identified 'rapid diagnosis' as the most important advantage of Al. 123 (45.7\%) participants considered concerns about potential medical errors and liability issues to be the most worrying aspects of Al.

CONCLUSION: According to our study, the use of Al technology in the diagnosis and treatment of breast disease and cancer seems to be beneficial for both physicians and patients. However, physicians have some concerns about possible medical errors and liability issues that Al might cause (Tab. 1, Ref. 25). Text in PDF www.elis.sk

KEY WORDS: breast diseases, artificial intelligence, cancer, surveys and questionnaires.
\end{abstract}

\section{Introduction}

The current scientific era is undergoing a digital revolution, where Artificial intelligence (AI) technologies play a crucial role and have become the touchstone of our digital age $(1,2)$. The deep learning of computers, machine learning, etc. used in the field of healthcare can all be collected under the heading of 'AI technologies'.

This rapid digitalization and increased opportunity to use AI is helping to innovate the approach to breast disease and cancer in medical sciences (3). Breast cancer is the most common malignancy in women and the leading cause of cancer death. Now, with the help of AI, there is more optimism for a universal resolution to this important public health problem $(4,5)$.

${ }^{1}$ Department of General Surgery, University of Health Sciences, Tepecik Training and Research Hospital, Izmir, Turkey, ${ }^{2}$ Department of Pathology, University of Health Sciences, Tepecik Training and Research Hospital, Izmir, Turkey, ${ }^{3}$ Izmir Provincial Health Directorate, Civil servant, and ${ }^{4}$ Department of Emergency Medicine, Izmir Dr. Suat Seren Chest Diseases and Surgeries Training and Research Hospital, Izmir, Turkey

Address for correspondence: H. Esin, MD, University of Health Sciences, Tepecik Training and Research Hospital, Department of General Surgery, Konak, Izmir, Turkey, Zip Code: 35020

Phone: +90533 5474817, Fax: +90232 4330756
Efforts to develop AI technologies for an early diagnosis and best treatment of breast disease and cancer are increasing, particularly in areas where image processing is possible, such as radiology and pathology $(6,7)$. The recently published study highlighted the great potential of AI technologies to change the routine practice of radiological breast cancer screening, so important in the early diagnosis of breast cancer (8). An early diagnosis of breast cancer and appropriate risk analysis are crucial for the treatment of this disease and there are new studies reporting the use of big data and AI to achieve an earlier diagnosis of breast cancer (9). In the multidisciplinary treatment of breast cancer, in addition to experience-based medicine, AI technologies are now being developed in the fields of surgery, oncology and radiation oncology, to offer the patients the opportunities for personalized treatment $(4,10,11)$.

All these technological advances in AI have historically changed the diagnosis, treatment, and management of breast disease. The aim of this study was to evaluate the impact of AI on approaches to breast disease and cancer among the physicians specializing in breast health in our country, with a national survey. Our survey examined the opinions held by such physicians on AI; their reservations, approaches and outlook for the future. As a novel study on this specific subject matter, we believe that it could fill an important research gap in national and international arenas. 
Tab. 1. The survey questions and answers.

\begin{tabular}{|c|c|c|}
\hline THE QUESTIONNAIRE & $\mathrm{n}$ & $\%$ \\
\hline \multicolumn{3}{|l|}{ What is your age? } \\
\hline $30-40$ & 63 & $(23.4 \%)$ \\
\hline $40-50$ & 105 & $(39 \%)$ \\
\hline $50-60$ & 78 & $(29 \%)$ \\
\hline $60-70$ & 23 & $(8.6 \%)$ \\
\hline \multicolumn{3}{|l|}{ What is your profession? } \\
\hline Surgeon & 92 & $(34.2 \%)$ \\
\hline Radiologist & 47 & $(17.5 \%)$ \\
\hline Pathologist & 51 & $(19 \%)$ \\
\hline Medical Oncologist & 34 & $(12.6 \%)$ \\
\hline Radiation Oncologist & 45 & $(16.7 \%)$ \\
\hline \multicolumn{3}{|l|}{ If you use AI in your specialist practice, how often do you use it? } \\
\hline I never use it. & 218 & $(81 \%)$ \\
\hline I use it on a daily basis. & 20 & $(7.4 \%)$ \\
\hline I use it on a weekly basis. & 14 & $(5.2 \%)$ \\
\hline I use it on a monthly basis & 11 & $(4.1 \%)$ \\
\hline I use it on a yearly basis & 6 & $(2.2 \%)$ \\
\hline \multicolumn{3}{|l|}{$\begin{array}{l}\text { Which specialization related to care of breast disease and cancer } \\
\text { do you think will be impacted by AI the soonest and the strongest? }\end{array}$} \\
\hline Surgeon & 29 & $(10.8 \%)$ \\
\hline Radiologist & 149 & $(55.4 \%)$ \\
\hline Pathologist & 26 & $(9.7 \%)$ \\
\hline Medical Oncologist & 45 & $(16.7 \%)$ \\
\hline Radiation Oncologist & 20 & $(7.4 \%)$ \\
\hline \multicolumn{3}{|l|}{$\begin{array}{l}\text { What is your greatest concern for the future related to the use of AI } \\
\text { in breast disease and cancer? (There may be more than one option.) }\end{array}$} \\
\hline Losing my job & 47 & $(17.5 \%)$ \\
\hline Increased medical error and liability issues & 123 & $(45.7 \%)$ \\
\hline Possible AI dependency & 106 & $(39.4 \%)$ \\
\hline Concerns about big data sharing & 95 & $(35.3 \%)$ \\
\hline Unethical decision-making or violations of ethical values & 107 & $(39.8 \%)$ \\
\hline I am not concerned & 47 & $(17.5 \%)$ \\
\hline Misdirection of artificial intelligence & 1 & $(0.4 \%)$ \\
\hline Who will have medicolegal responsibility? & 1 & $(0.4 \%)$ \\
\hline Legal approaches on legal liability & 1 & $(0.4 \%)$ \\
\hline \multicolumn{3}{|c|}{$\begin{array}{l}\text { What is the most important advantage gained by using } \mathrm{AI} \text { in your approach } \\
\text { to breast disease and cancer? (There may be more than one option.) }\end{array}$} \\
\hline Rapid diagnosis & 169 & $(70.3 \%)$ \\
\hline Economical and inexpensive response & 69 & $(25.7 \%)$ \\
\hline Evaluation of the patient in more detail & 145 & $(53.9 \%)$ \\
\hline Examination of higher number of patients & 135 & $(50.2 \%)$ \\
\hline Ease of accessibility & 85 & $(31.6 \%)$ \\
\hline \multicolumn{3}{|l|}{ What is your knowledge about $\mathrm{AI}$ in breast disease and cancer? } \\
\hline I have no information & 73 & $(27.1 \%)$ \\
\hline I have only a little knowledge & 133 & $(49.4 \%)$ \\
\hline I am moderately knowledgeable. & 55 & $(20.4 \%)$ \\
\hline I am very knowledgeable & 8 & $(3 \%)$ \\
\hline \multicolumn{3}{|l|}{ Have you ever used $\mathrm{AI}$ in your practice for breast disease and cancer? } \\
\hline I have never used it & 217 & $(80.7 \%)$ \\
\hline I use it occasionally & 33 & $(12.3 \%)$ \\
\hline I use it moderately & 13 & $(4.8 \%)$ \\
\hline I use it frequently & 6 & $(2.2 \%)$ \\
\hline \multicolumn{3}{|l|}{ Do you believe it is necessary to use $\mathrm{AI}$ in breast disease and cancer? } \\
\hline It is not necessary at all & 3 & $(1.1 \%)$ \\
\hline It is somewhat necessary. & 75 & $(27.9 \%)$ \\
\hline It is moderately necessary. & 88 & $(32.7 \%)$ \\
\hline It is very necessary. & 73 & $(27.1 \%)$ \\
\hline I have no idea. & 30 & $(11.2 \%)$ \\
\hline
\end{tabular}

\section{Materials and methods}

The questionnaire used for this survey study was designed by a team of four people specializing in the treatment of breast disease and cancer in our hospital and using Google Drive. A test version was launched with a group of 20 specialist physicians from different branches and necessary improvements were made based on their feedback.

The approval for this survey was obtained from the local ethics committee of the Health Sciences University, Izmir Tepecik Training and Research Hospital.

The final questionnaire was sent to the members of the Turkish Federation of Breast Disease Associations (MHDF) by e-mail, with a brief information, between 26 May and 27 June 2021. Members of the Federation (MHDF) comprised general surgeons (breast surgeons), radiologists, pathologists, medical oncologists, radiation oncologists (registrars, associate professors, professors) working in different parts of the country. Respondents were denied access to the survey for the second time. Our survey was conducted online only and no gifts and/or payments were made to the respondents.

Instead of referring to individual terms such as: algorithm, deep learning or machine learning, the umbrella phrase 'AI' was used throughout. The questionnaire consisted of 20 questions in total, 19 of which were closed-ended and one of which was open-ended. The demographic characteristics of the participants and their attitudes to using AI technologies in the care of breast disease and cancer were investigated, including their approaches, daily practice, and outlook for the future. Respondents, who did not fill out the questionnaire completely and those, who returned it after the deadline were excluded from the study. As respondents were free to decide whether to complete the questionnaire, its completion was considered as tacit consent for the use of the questionnaire data.

\section{Statistics}

In our study, the results are presented as a descriptive statistical analysis. 
Tab. 1.

\begin{tabular}{|c|c|c|}
\hline \multicolumn{3}{|c|}{$\begin{array}{l}\text { Do you believe that } \mathrm{AI} \text { in breast disease will improve the fields of } \\
\text { application within your area of expertise? }\end{array}$} \\
\hline It will bring no improvement & 3 & $(1.1 \%)$ \\
\hline It will bring a small improvement. & 37 & $(13.8 \%)$ \\
\hline It will bring a moderate improvement. & 108 & $(40.1 \%)$ \\
\hline It will bring great improvement. & 103 & $(38.3 \%)$ \\
\hline I have no idea. & 18 & $(6.7 \%)$ \\
\hline \multicolumn{3}{|c|}{$\begin{array}{l}\text { Will AI have a noticeable impact in } \leq 5 \text { years in terms of diagnosis } \\
\text { and treatment of breast disease and cancer? }\end{array}$} \\
\hline It will have no impact. & 11 & $(4.1 \%)$ \\
\hline It will have some impact. & 98 & $(36.4 \%)$ \\
\hline It will have a moderate impact. & 93 & $(34.6 \%)$ \\
\hline It will have a great impact. & 49 & $(18.2 \%)$ \\
\hline I have no idea. & 18 & $(6.7 \%)$ \\
\hline \multicolumn{3}{|c|}{$\begin{array}{l}\text { Do you believe that } \mathrm{AI} \text { will have a noticeable impact on the } \\
\text { diagnosis and treatment of breast disease and cancer in } \leq 10 \text { years? }\end{array}$} \\
\hline It will have no impact. & 1 & $(0.4 \%)$ \\
\hline It will have some impact. & 34 & $(12.6 \%)$ \\
\hline It will have a moderate impact. & 76 & $(28.3 \%)$ \\
\hline It will have a great impact. & 144 & $(53.5 \%)$ \\
\hline I have no idea. & 14 & $(5.2 \%)$ \\
\hline \multicolumn{3}{|c|}{$\begin{array}{l}\text { How would you evaluate the effectiveness of AI in the clinical diagnosis } \\
\text { of breast disease and cancer? }\end{array}$} \\
\hline It is not effective at all. & 14 & $(5.2 \%)$ \\
\hline It is somewhat effective. & 59 & $(21.9 \%)$ \\
\hline It is moderately effective. & 97 & $(36.1 \%)$ \\
\hline It is very effective. & 53 & $(19.7 \%)$ \\
\hline I have no idea. & 46 & $(17.1 \%)$ \\
\hline \multicolumn{3}{|c|}{$\begin{array}{l}\text { In terms of breast disease and cancer, does AI provide advantages in the } \\
\text { early diagnosis and risk analysis of breast cancer with the use of big data? }\end{array}$} \\
\hline It gives no advantages. & 3 & $(1.1 \%)$ \\
\hline It gives some advantages. & 39 & $(14.5 \%)$ \\
\hline It gives moderate advantages. & 87 & $(32.3 \%)$ \\
\hline It gives many advantages. & 122 & $(45.4 \%)$ \\
\hline I have no idea. & 18 & $(6.7 \%)$ \\
\hline \multicolumn{3}{|c|}{$\begin{array}{l}\text { How would you evaluate the effectiveness of AI in breast cancer } \\
\text { screening? }\end{array}$} \\
\hline It is not effective at all. & 3 & $(1.1 \%)$ \\
\hline It is somewhat effective. & 48 & $(17.8 \%)$ \\
\hline It is moderately effective. & 91 & $(33.8 \%)$ \\
\hline It is very effective. & 85 & $(31.6 \%)$ \\
\hline I have no idea. & 42 & $(15.6 \%)$ \\
\hline \multicolumn{3}{|c|}{$\begin{array}{l}\text { How would you evaluate the effectiveness of AI in the pathological } \\
\text { evaluation of breast disease? }\end{array}$} \\
\hline It is not effective at all. & 12 & $(4.5 \%)$ \\
\hline It is somewhat effective. & 56 & $(20.8 \%)$ \\
\hline It is moderately effective. & 88 & $(32.7 \%)$ \\
\hline It is very effective. & 56 & $(20.8 \%)$ \\
\hline I have no idea. & 57 & $(21.2 \%)$ \\
\hline \multicolumn{3}{|c|}{$\begin{array}{l}\text { How would you evaluate the effectiveness of } \mathrm{AI} \text { in the radiological } \\
\text { evaluation of breast disease? }\end{array}$} \\
\hline It is not effective at all. & 7 & $(2.6 \%)$ \\
\hline It is somewhat effective. & 35 & $(13 \%)$ \\
\hline It is moderately effective. & 93 & $(34.6 \%)$ \\
\hline It is very effective. & 99 & $(36.8 \%)$ \\
\hline I have no idea. & 35 & $(13 \%)$ \\
\hline \multicolumn{3}{|c|}{$\begin{array}{l}\text { How reliable do you find } \mathrm{AI} \text { in guiding treatment for breast disease } \\
\text { and cancer? }\end{array}$} \\
\hline It is not reliable at all. & 13 & $(4.8 \%)$ \\
\hline It is somewhat reliable. & 89 & $(33.1 \%)$ \\
\hline It is moderately reliable. & 150 & $(55.8 \%)$ \\
\hline It is very reliable. & 17 & $(6.3 \%)$ \\
\hline
\end{tabular}

\section{Results}

The survey was sent to a total of 1,890 physicians via e-mail, and 269 (14.2\%) participants completed all the questions. The highest rate of reply came from the general surgeons: 92 (34.2\%). $149(55.4 \%)$ of the participants defined radiology as the specialty related to breast disease and cancer most affected by AI. 123 (45.7 \%) participants considered concerns about potential medical errors and liability issues to be the most worrying aspects of AI.

In the answer to the same open-ended question on where the medicolegal responsibility would lie, one participant mentioned his worries about legal responsibility, while the second participant expressed concerns about being misled by AI.

$169(70.3 \%)$ of the respondents believed the most important advantage of AI to be a rapid diagnosis. When participants were questioned about their knowledge of AI use in breast disease and cancer, 133 (49.4\%) reported having a little knowledge while $73(27.1 \%)$ had no knowledge at all. 217 (80.7\%) participants claimed never to have actually used AI for breast care in daily practice. When asked about the necessity of using AI in this area, $88(32.7 \%)$ of the participants thought that it was moderately necessary. 108 (40.1\%) participants thought that AI would improve their specializations in breast diseases to a moderate degree while 103 (38.3\%) thought it could bring great improvement.

49 physicians (18.2\%) predicted that the impact of AI on the diagnosis and treatment of breast disease would be very high within $\leq 5$ years, and $144(53.5 \%)$ expected this to happen within $\leq 10$ years.

93 of the participants $(34.6 \%)$ defined the effectiveness of AI in clinical diagnosis as moderately effective. $122(45.4 \%)$ of the participants thought that the use of $\mathrm{AI}$ and big data could provide many advantages for an early diagnosis and risk analysis of breast cancer. 87 (32.3\%) participants defined the effectiveness of $\mathrm{AI}$ in screening programs to be moderate, while $98(36.7 \%)$ believed AI to be very effective in breast radiology. AI was found to be moderately reliable as a treatment guide by $150(55.8 \%)$ participants. 
Tab. 1.

\begin{tabular}{|c|c|c|}
\hline \multicolumn{3}{|l|}{$\begin{array}{l}\text { How do you think AI should be used in the future for the treatment } \\
\text { of breast disease and cancer? }\end{array}$} \\
\hline I find the potential use of AI disturbing. & 4 & $(1.5 \%)$ \\
\hline I believe it should be used partially. & 60 & $(22.3 \%)$ \\
\hline $\begin{array}{l}\text { I believe there should be an approx. } 50 / 50 \text { collaboration between } \\
\text { the physician and AI. }\end{array}$ & 195 & $(72.5 \%)$ \\
\hline I believe all the treatment should be handled by AI. & 5 & $(1.9 \%)$ \\
\hline I have no idea. & 5 & $(1.9 \%)$ \\
\hline \multicolumn{3}{|l|}{$\begin{array}{l}\text { Does the future of AI use in the treatment of breast disease and } \\
\text { cancer alarm you? }\end{array}$} \\
\hline I am not at all alarmed. & 150 & $(55.8 \%)$ \\
\hline I am a little alarmed. & 70 & $(26 \%)$ \\
\hline I am moderately alarmed. & 30 & $(11.2 \%)$ \\
\hline I am extremely alarmed. & 3 & $(1.1 \%)$ \\
\hline I have no idea. & 16 & $(5.9 \%)$ \\
\hline
\end{tabular}

of these and other system-related challenges (14). Indeed, thanks to these technologies, a better and quicker service can be offered to a larger number of patients. Schwalbe N. et al. suggest that simultaneous advances in the infrastructure of information technology and mobile computing power are a cause for optimism that AI can be used to address health challenges in many societies. They emphasize the increasing importance of AI technologies in early diagnosis and rapid treatment, as well as for detailed analysis and determining the prognosis of a disease (15).

There is certainly a paradigm shift in the management and direction of general

In our survey, $195(72.5 \%)$ respondents identified the need for a 50/50 collaboration between physician and AI in the future. When asked whether the future AI use in treating breast disease and cancer was alarming, 150 (55.8\%) participants stated that they were not afraid at all. The survey questions and answers are shown in Table 1.

\section{Discussion}

Our results showed that doctors specializing in the treatment of breast disease believed that using AI for the breast disease and cancer is of benefit to both physicians and patients. Currently, most physicians in our survey do not use AI; however, they expect the use of AI for breast disease to increase over time. It was also suggested that a 50/50 collaboration between physicians and AI seemed appropriate for the future. While physicians were not alarmed by the idea of using AI in the future, they did have important reservations regarding ethics, medical errors and legal responsibility.

To our knowledge, this survey on the use of AI by physicians working in the field of breast disease and cancer is the first such survey to be carried out either nationally or internationally.

According to our survey, it seems that AI technologies will improve breast disease and cancer care for both physicians and patients. The global population is growing rapidly, and the incidence of breast cancer is on the rise; therefore, the requirements (labor and financial needs) for breast disease screening, diagnosis and treatment are constantly increasing.

In fact, breast cancer currently accounts for approximately $30 \%$ of malignancies in women (12). According to one study, physicians spend $27 \%$ of their clinic time on face-to-face communication with their patients, but $49 \%$ of their time on the computer reviewing patient records and carrying out office work (13). Besides this paperwork, physicians must constantly strive to keep up to date with a constantly renewing bank of medical knowledge.

These stark realities highlight the difficulties inherent to managing important health problems, namely, the optimal diagnosis and treatment of breast disease and cancer. Fortunately, it seems that AI-driven healthcare technologies can be used to address many health affairs and AI is thought capable of reducing the errors of human clinical practice (16). When asked about the urge to use AI in breast disease and cancer, the participants in our study defined it as either moderately necessary $(32.7 \%)$ or very necessary $(27.1 \%)$.

In addition, the use of AI was thought to bring advantages for patients such as a rapid diagnosis (70\%), a more detailed evaluation $(54.3 \%)$, and examination of a larger number of patients (49.8\%). Our survey concluded that the use of AI in breast disease would lead to improvements in medical specialization fields at either a high $(38.3 \%)$ or moderate $(40.1 \%)$ level. These results showed that physicians could manage a larger number of patients with the help of AI technologies. In the future, if more appropriate patient care can be provided, as physicians work together with AI to treat breast cancer and disease, the increasing needs of breast cancer patients in society could be met. Early and detailed diagnosis of breast cancer will be possible; better treatment of more patients can be planned. We believe that such technological developments can help breaking the tyrannical hold breast cancer has over women.

Our study showed that while AI is not currently used to a large extent in the treatment of breast diseases and cancer, its use in this field is expected to increase over the next decade. Breast disease is reported as one of the most common types of disease seen in surgical outpatient clinics (17). Meanwhile, information technology and digitalization are developing in the field of healthcare, and there are efforts to use it more extensively, especially in breast disease $(6,7,18)$. As far as we can observe, AI is not widely practiced in all specialties that manage breast disease and cancer care. However, it is under an intensive research and there are high expectations that physicians will be able to use AI to assist them in their daily practices soon $(14,15,19)$. Despite these high expectations, the study conducted in Germany reported that there are still few practical applications of artificial intelligence in the clinical use. In the same paper, physicians argued the need for robust studies on the practical application of AI (20). In our study, $81.3 \%$ of the participants reported not using AI technology in their daily work with breast disease. This situation is similar according to one in literature. However, our participants also reported their expecta- 
tion that the visible effect of AI on breast disease and cancer care would continue to increase over the next 5-10 years. Based on these results, it seems that our participants expect the impact of AI to be very strong in 10 years' time, although not in the near future or within 5 years.

Furthermore, our study participants reported being unafraid of using AI technologies in the care of breast diseases and cancer in future and felt that it would be appropriate to work in cooperation with AI. However, despite this willingness, they did have some concerns. Each new technological innovation leads to a change in societal attitudes, especially when this technology may replace an individual's job, so an increase in the anxiety felt by physicians is understandable. There were similar concerns when computers were first used in medicine (21). However, AI differs from computers as AI technology that can directly replace the physician's job is actually being developed $(1,2)$. Previously, it was thought that AI would replace doctors (21), although this has not yet happened. Recent developments on this issue have been rapid but have still not come to fruition. In the recent survey, health workers reported their concerns that AI technologies would take over their jobs (22). In another study, the majority of doctors refuted the idea that artificial intelligence would replace them, and the same study reported that physicians believed AI could be of benefit to them in the future for both diagnosis and treatment (23). In another published study, physicians identified a high cost and a lack of human touch as disadvantages of AI, despite being aware of other advantages in medical practice (24).

In our study, approximately $55.8 \%$ of the participants stated that they were not alarmed by AI at all and emphasized that it would be appropriate to work in full cooperation (50/50) with AI in future. Clearly, the huge amount of data produced on breast disease and breast cancer can be more easily processed and applied with the help of AI, thus providing great convenience for both patients and physicians. However, some potential ethical issues of AI use in healthcare are still unresolved. In addition to ethics, our questionnaire describes physicians' concerns about medical errors and the allocation of responsibility. It seems likely that the focus will be on resolving these important issues as the use of AI technologies in the approach to breast disease is further developed.

Our survey judged that the field of specialization within breast healthcare affected the soonest and most profoundly by AI would be radiology. Studies on image processing have been carried out for many years within this discipline, with radiology image processing technologies described in literature as the most commonly studied use of AI in medicine $(6,19,25)$. Recent studies have reported successful screening programs using AI for the early diagnosis of breast cancer (8) and these results have the potential to fundamentally change screening procedures. These are exciting developments in the early diagnosis of breast cancer. In our study, radiology was selected by a wide margin as the branch of specialization that would benefit the most by AI compared to other specialties. Therefore, we conclude that in this digital age, physicians should closely follow literature for developments in radiology.
Limitations: This original study has some limitations. Firstly, subgroup analysis could not be performed due to low numbers in the groups. Secondly, the survey questions and their resulting answers are somewhat subjective. Last of all, doctors from other specialty roles involved in the treatment of breast cancer were not included in the survey.

\section{Conclusion}

Our survey concludes that the use of AI technology in the care of breast disease and cancer is beneficial for both physicians and patients. Most physicians in this field do not use AI in their daily practice but consider it appropriate to work in collaboration with $\mathrm{AI}$ in the future. Physicians should not be reluctant to adopt AI technologies in their professional lives. Physicians have identified concerns about the use of AI in relation to ethics, medical errors, and the question of responsibility. They also expect AI to impact the branch of radiology the soonest and most deeply. There is a need for further well-planned, more comprehensive, and detailed survey studies on this popular topic.

\section{References}

1. Prestes E. The Age of Digital Interdependence- Report of the UN Secretary-General's High-level Panel on Digital Cooperation. 2019.

2. Kickbusch I, Agrawal A, Jack A, Lee N, Horton R. Governing health futures 2030: growing up in a digital world-a joint The Lancet and Financial Times Commission. Lancet 2019; 394: 1309.

3. Cardoso MJ, Houssami N, Pozzi G, Séroussi B. Artificial intelligence (AI) in breast cancer care - Leveraging multidisciplinary skills to improve care. Breast 2020; 56: 110-113.

4. Bouaud J, Pelayo S, Lamy J-B, Prebet C, Ngo C, Teixeira L et al. Implementation of an ontological reasoning to support the guideline-based management of primary breast cancer patients in the DESIREE project. Artif Intell Med 2020; 108: 101922.

5. Carter S, Rogers W, Win K, Frazer H, Richards B, Houssami N. The ethical, legal and social implications of using artificial intelligence systems in breast cancer care. The Breast 2019; 49.

6. Yap MH, Goyal M, Osman F, Martí R, Denton E, Juette A et al. Breast ultrasound region of interest detection and lesion localisation. Artif Intell Med 2020; 107: 101880.

7. Carvalho ED, Filho AOC, Silva RRV, Araújo FHD, Diniz JOB, Silva AC, et al. Breast cancer diagnosis from histopathological images using textural features and CBIR. Artif Intell Med 2020; 105: 101845.

8. McKinney SM, Sieniek M, Godbole V, Godwin J, Antropova N, Ashrafian $\mathbf{H}$ et al. International evaluation of an AI system for breast cancer screening. Nature 2020; 577:89-94.

9. Stark GF, Hart GR, Nartowt BJ, Deng J. Predicting breast cancer risk using personal health data and machine learning models. Plos one 2019; 14: 02226765 .

10. Poortmans PMP, Takanen S, Marta GN, Meattini I, Kaidar-Person O. Winter is over: The use of Artificial Intelligence to individualise radiation therapy for breast cancer. Breast 2019; 49: 194-200.

11. Shimizu H, Nakayama KI. Artificial intelligence in oncology. Cancer Sci 2020; 111: 1452-1460. 


\section{1-196}

12. Bray F, Ferlay J, Soerjomataram I, Siegel RL, Torre LA, Jemal A. Global cancer statistics 2018: GLOBOCAN estimates of incidence and mortality worldwide for 36 cancers in 185 countries. CA Cancer J Clin 2018; 68: 394-424.

13. Amisha, Malik P, Pathania M, Rathaur VK. Overview of artificial intelligence in medicine. J Family Med Prim Care 2019; 8: 2328-2331.

14. Wahl B, Cossy-Gantner A, Germann S, Schwalbe NR. Artificial intelligence (AI) and global health: how can AI contribute to health in resource-poor settings? BMJ Glob Health 2018; 3: e000798.

15. Schwalbe N, Wahl B. Artificial intelligence and the future of global health. Lancet 2020; 395: 1579-1586.

16. Jha S, Topol EJ. Adapting to Artificial Intelligence: Radiologists and Pathologists as Information Specialists. JAMA 2016; 316: 2353-2354.

17. Emiroğlu M, İnal A, Sert İ, Karaali C, Peker K, İlhan E et al. Surgeons' Approaches and Professional Perspectives on Breast Masses: A National Survey in Turkey. J Breast Health 2015; 11: 76-80.

18. Guo Y, Hao Z, Zhao S, Gong J, Yang F. Artificial Intelligence in Health Care: Bibliometric Analysis. J Med Internet Res 2020; 22: e18228.

19. Pakdemirli E. Artificial intelligence in radiology: friend or foe? Where are we now and where are we heading? Acta Radiol Open 2019; 8: 2058460119830222.
20. Maassen O, Fritsch S, Palm J, Deffge S, Kunze J, Marx G et al. Future Medical Artificial Intelligence Application Requirements and Expectations of Physicians in German University Hospitals: Web-Based Survey. J Med Internet Res 2021; 23: e26646.

21. Chockley K, Emanuel E. The End of Radiology? Three Threats to the Future Practice of Radiology. J Am Coll Radiol 2016; 13: 1415-1420.

22. Abdullah R, Fakieh B. Health Care Employees' Perceptions of the Use of Artificial Intelligence Applications: Survey Study. J Med Internet Res 2020; 22: e17620.

23. Johnston SC. Anticipating and Training the Physician of the Future: The Importance of Caring in an Age of Artificial Intelligence. Acad Med 2018; 93: 1105-1106.

24. Maskara R, Bhootra V, Thakkar D, Nishkalank N. A study on the perception of medical professionals towards artificial intelligence. Int $\mathrm{J}$ Multidiscip Res Dev 2017; 4: 34-39.

25. Scheetz J, Rothschild P, McGuinness M, Hadoux X, Soyer HP, Janda $M$ et al. A survey of clinicians on the use of artificial intelligence in ophthalmology, dermatology, radiology and radiation oncology. Sci Rep 2021; 11: 5193.
Received October 2, 2021. Accepted November 23, 2021. 